\title{
Intracranial Arterial Calcification in Black Africans with Acute Ischaemic Stroke
}

\author{
Richard B. Olatunji Ademola J. Adekanmi Ayotunde O. Ogunseyinde \\ Department of Radiology, College of Medicine, University of Ibadan, University College \\ Hospital, Ibadan, Nigeria
}

\author{
Keywords \\ Vascular calcification · Carotid siphon · Intracranial atherosclerotic disease · Computed \\ tomography $\cdot$ Nigeria
}

\begin{abstract}
Background: Intracranial arterial calcification (IAC), a recognized marker of atherosclerosis on cranial computed tomography (CT), is an independent risk factor for ischaemic stroke. This study aimed to determine the prevalence, distribution, severity, and associations of IAC in adults with acute ischaemic stroke (AIS) at the University College Hospital, Ibadan, Nigeria. Methods: Cranial CT images of 130 consecutive adults who presented with AIS were acquired on a 64-slice multi-detector Toshiba Aquilion scanner and evaluated for IAC in bone window on Vitrea ${ }^{\circledR}$ software using a semi-quantitative scoring method for extent, thickness, and length of calcifications in the large intracranial arteries. Associations of IAC with clinical and laboratory data were determined by statistical analysis at $p<0.05$. Results: There were 71 males (54.6\%), and the mean age of all patients was $63.0 \pm 13.2$ years. Hypertension was the most common risk factor (83.1\%). IAC was found in 121 patients (93.1\%), predominantly in the carotid siphon (86.1\%) followed by the intracranial vertebral arteries $(9.3 \%)$, middle cerebral arteries $(2.4 \%)$, basilar artery (1.2\%), and the anterior cerebral arteries (1\%). The burden of IAC ranged from mild $(17.4 \%)$ to moderate $(52.1 \%)$ to severe $(30.6 \%)$. Age $(p<0.001)$, diastolic blood pressure $(p=0.037)$, and alcohol use (0.046) were significantly different among the patients with mild, moderate, and severe degrees of IAC. IAC was associated with age $(p<$ $0.001)$, hypertension $(p=0.03)$, diabetes mellitus $(p=0.02)$, hyperlipidaemia $(p=0.04)$, and alcohol use $(p<0.001)$ but not with sex $(p=0.35)$. Conclusions: The burden of IAC is very high among native African patients with AIS and preferentially involves proximal inflow arteries. Therefore, the role of large vessel atherosclerosis in ischaemic stroke in native Africans should be explored in future multinational, multimodality studies.
\end{abstract}



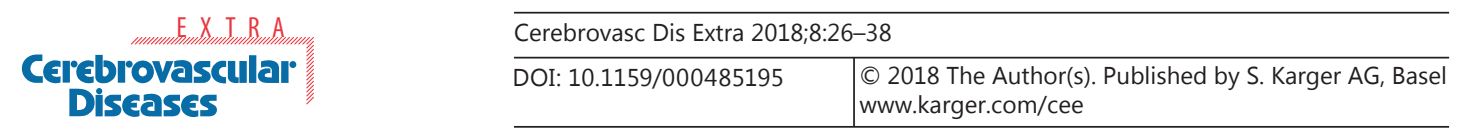

Olatunji et al.: Intracranial Arterial Calcification in Black Africans with Acute Ischaemic Stroke

\section{Introduction}

Stroke is one of the two leading causes of mortality globally and accounts for $9.7 \%$ of all deaths worldwide [1]. The incidence of stroke is on the increase in low-middle-income countries and has surpassed the incidence in high-income countries [2]. Ischaemic stroke is the more common type globally and intracranial atherosclerotic stenosis of the major arteries is the most common proximate mechanism worldwide [3]. Vascular calcifications are known as an integral part of the atherosclerotic process and occur in $80-90 \%$ of atheromatous lesions [4].

Calcifications of the intracranial arteries are frequently observed in computed tomography (CT) images of the brain and have been identified as an independent risk factor for stroke [5]. The prevalence of intracranial arterial calcification (IAC) has been studied in other parts of the world and is found to be higher in African Americans, Asians, and Hispanics than in Caucasians [6-8]. However, extrapolating data of African Americans as representative of the entire black race in stroke research may be misleading because native Africans in thirdworld settings do not necessarily share similar genetic, socioeconomic, and environmental characteristics with diaspora Africans.

Therefore, this study aims to provide data on the prevalence, characteristics, and associations of IAC as seen on cranial CT scans among a homogeneous native black population with acute ischaemic stroke (AIS) in a large city of sub-Saharan Africa.

\section{Methods}

This cross-sectional study was performed at the University College Hospital (UCH) Ibadan between April 2013 and March 2014. The UCH is an 850-bed tertiary care centre which serves patients from the entire country of Nigeria in sub-Saharan West Africa with an estimated population of 180 million people. It is located in Ibadan, a large city with an estimated local population of 3 million people in Southwest Nigeria, dominated by the Yoruba ethnic group.

Study participants were adults with clinically suspected AIS or transient ischaemic attack referred for cranial CT scans at the Radiology Department of the UCH, Ibadan. Only patients older than 18 years at the time of the CT scan were included in the study. All adults with haemorrhagic stroke; post-traumatic infarcts; infarcts from other nonspontaneous causes such as post-meningitis, post-vasculitis, and haemoglobinopathy; atrial fibrillation; myocardial infarction; and those whose CT scans were not suitable for analysis were excluded from the study.

\section{Clinical Evaluation}

The following variables for each subject were entered into a database: age, gender, previously identified stroke risk factors or those discovered during hospitalization including hypertension (antihypertensive treatment or systolic blood pressure $>140 / 90 \mathrm{~mm} \mathrm{Hg}$ or diastolic blood pressure $>90 \mathrm{~mm}$ Hg before hospitalization), diabetes (insulin or oral diabetic therapy or fasting blood glucose $>7.8 \mathrm{mmol} / \mathrm{L}$ on two occasions during hospitalization), hyperlipidaemia (lipid-lowering treatment or low-density lipoprotein cholesterol $>1 \mathrm{~g} / \mathrm{L}$ ), current smoking, regular alcohol consumption ( $>2$ alcoholic drinks daily), and peripheral artery disease (defined as history of intermittent claudication). 


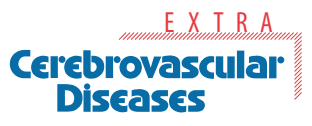

Fig. 1. Schematic diagrams showing grading of extent, thickness, and length of intracranial arterial calcifications on cranial computed tomography (CT). Hatched areas show calcifications. Crosses show electronic calipers.

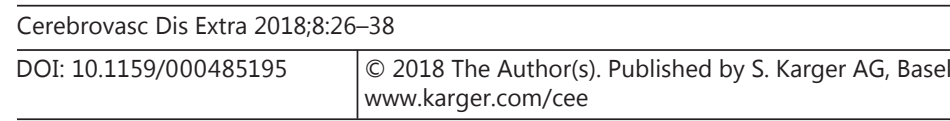

Olatunji et al.: Intracranial Arterial Calcification in Black Africans with Acute Ischaemic Stroke

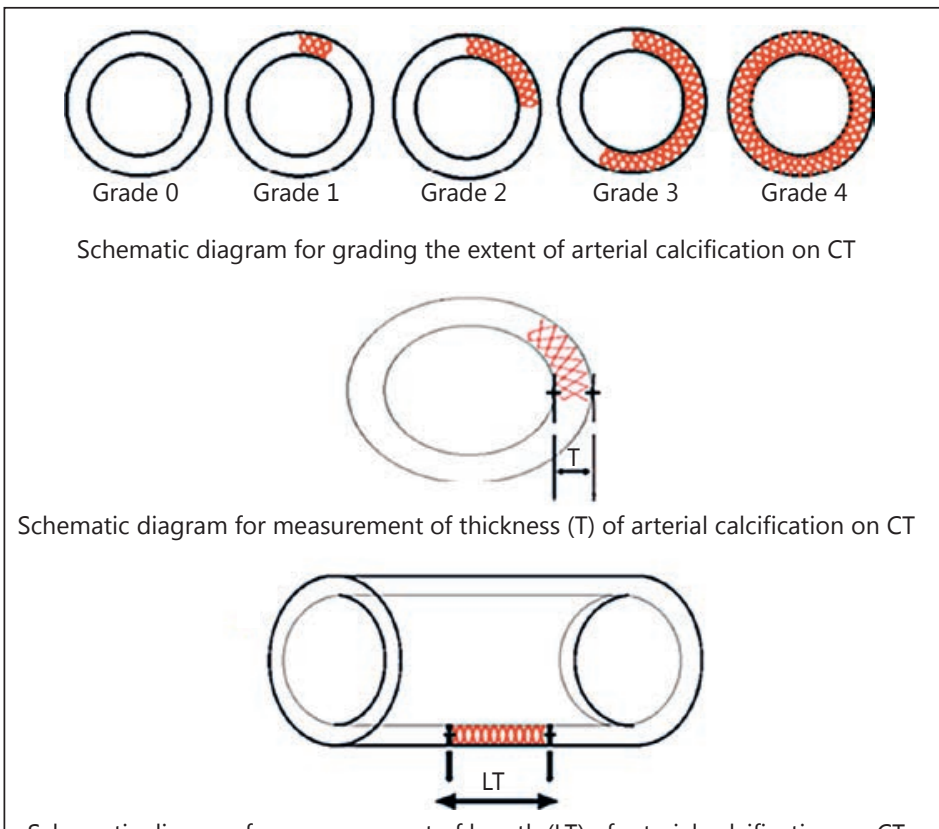

Schematic diagram for measurement of length (LT) of arterial calcification on CT

\section{CT Evaluation}

Consecutive patients who met the eligibility criteria had cranial CT scans acquired according to standard practice on a 64-slice scanner (Toshiba Aquilion, Japan) using the volumetric acquisition protocol with these parameters: slice thickness of $0.625 \mathrm{~mm}$ with no interval between slices; maximum kilovoltage of $140 \mathrm{kV} ; 170 \mathrm{~mA}$ tube current; 2 s per rotation, and field of view of $24 \mathrm{~cm}$ that covered the entire brain from the foramen magnum inferiorly to the cranial vertex superiorly. The cranial CT data were processed and analyzed by a single radiologist using the Vitrea ${ }^{\circledR}$ software Version 2 (Vital Images, Inc., Minnetonka, MN, USA) to avoid inter-observer error.

\section{IAC Evaluation}

Calcification in the wall of the intracranial artery was defined as a hyperdense focus with a density greater than 130 Hounsfield units on bone window images (WW: 3,000, WL: 500) [9]. The 5-point scale semi-quantitative scoring system proposed by Babiarz et al. [10] for extent (0-4) and thickness (0-4) of any calcification in the intracranial arteries was modified to include length of calcification (0-4) and used to evaluate the IAC on bone window images of non-contrast cranial CT studies. The extent of calcification was graded as 0 (no calcification); 1 (dot of calcification); 2 (crescentic area of calcification $<90$ degrees of arterial wall circumference); 3 (calcification from 90 to 270 degrees of arterial wall circumference); and 4 (calcification spanning 270-360 degrees of arterial wall circumference) as shown in Figures 1 and 2. The electronic callipers of the Vitrea ${ }^{\circledR}$ software was used to measure thickness of calcification which was graded as 0 (no calcification); 1 (1-mm-thick calcification); 2 (2-mm thick calcification); 3 (3-mm thick calcification); and 4 (>3-mm thick calcification). Likewise, the length of calcification was graded as 0 (no calcification); 1 (1-mm-long calcification); 2 (2-mm long calcification); 3 (3-mm long calcification); and 4 (>3-mm long calcification). The assessment included the intracranial internal carotid artery (ICA) (divided into 3 segments, namely pre-cavernous, cavernous, and post-cavernous), anterior cerebral artery (ACA), 


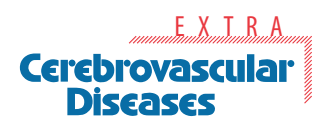

\begin{tabular}{l|l}
\hline Cerebrovasc Dis Extra 2018:8:26-38 \\
\hline DOI: 10.1159/000485195 & $\begin{array}{l}\text { @ } 2018 \text { The Author(s). Published by S. Karger AG, Basel } \\
\text { www.karger.com/cee }\end{array}$ \\
\hline
\end{tabular}

Olatunji et al.: Intracranial Arterial Calcification in Black Africans with Acute Ischaemic Stroke
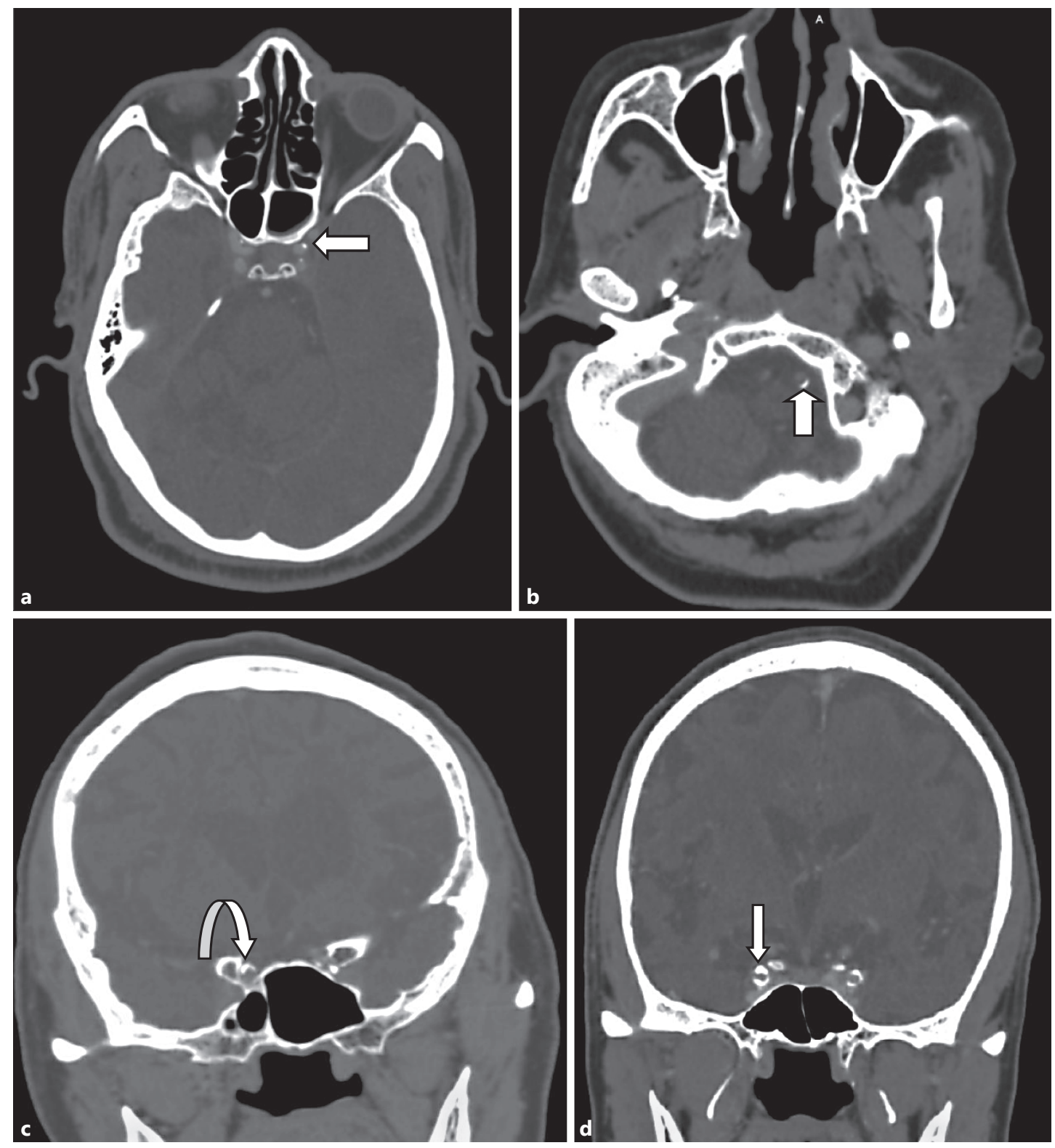

Fig. 2. Axial (a, b) and coronal reformatted (c, d) cranial computed tomography bone window images showing grades 1-4 of extent of intracranial arterial calcifications, respectively. The arrow in a shows a dot of calcification (grade 1) in the left cavernous internal carotid artery (ICA); the arrow in $\mathbf{b}$ shows a crescentic calcification (grade 2) in the left vertebral artery; the curved arrow in c shows a semi-circular calcification (grade 3) in the right cavernous ICA; and the arrow in $\mathbf{d}$ shows a fairly circular calcification (grade 4) in the right cavernous ICA.

middle cerebral artery (MCA), vertebral artery (VA) as well as the basilar artery (BA). Each artery was evaluated in the plane where it had the most circular cross-section for the thickness and extent of calcifications, respectively. The plane where the vessel was most tubular was used to evaluate the length of calcification. All calcified plaques in these entire vessels were evaluated and scored systematically. Besides separate scores for extent, thickness, and length, a composite CT score (sum of extent, thickness, and length) was also obtained as a modifi- 
Table 1. Scoring and severity of intracranial arterial calcification (IAC)

a Scoring of IAC

\begin{tabular}{lllr}
\hline Grade & Extent & \multicolumn{2}{l}{ Calcification } \\
\cline { 3 - 3 } & & Thickness, mm & Length, mm \\
\hline 0 & No calcification & 0 & 0 \\
1 & Dot of calcification & 1 & 1 \\
2 & Crescentic calcification $\left(<90^{\circ}\right.$ of circumference) & 2 & 2 \\
3 & Calcification $90-270^{\circ}$ of circumference & 3 & 3 \\
4 & Calcification $270-360^{\circ}$ of circumference & $>3$ & $>3$ \\
\hline
\end{tabular}

b Severity of IAC

\begin{tabular}{ll}
\hline Severity & Composite score \\
\hline Absent & 0 \\
Mild & $1-4$ \\
Moderate & $5-8$ \\
Severe & $9-12$ \\
\hline
\end{tabular}

cation of the method described by Mak et al. [11] as shown in Table 1a. Based on the tabulated scoring results of all evaluated intracranial arteries of a patient, the highest composite CT score was chosen to represent the degree of intracranial atherosclerosis in the individual subject. The severity of IAC was classified based on the highest composite CT score with 0 graded as absent, $1-4$ as mild, $5-8$ as moderate, and $9-12$ as severe degree of atherosclerosis [11] as shown in Table $1 b$.

\section{Data Analysis}

Data were analyzed using SPSS (Statistical Package for Social Sciences) Version 20 for Windows ${ }^{\circledR}$ (Chicago, IL, USA). The $\chi^{2}$ test was used to determine the association between quantitative variables. The Student $t$ test and one-way ANOVA were used to evaluate the association between continuous variables as appropriate. Logistic regression analysis was also performed to determine independent predictors of the number and severity of IAC. Statistical tests were conducted at a $5 \%$ level of significance.

\section{Results}

Of the 130 study participants, $71(54.6 \%)$ were males and $59(45.4 \%)$ were females. About half of the patients $(50.8 \%)$ were younger than 65 years, with an overall mean age of $63.0 \pm 13.2$ years (range from 25 to 92 years) as shown in Table 2 with other demographic and clinical characteristics. The mean age of the male patients ( $62.4 \pm 13.0$ years) was not significantly difference from that of the female patients ( $63.7 \pm 13.6$ years, $p=0.58$ ). Most of the patients were hypertensive (83.1\%) but without a prior episode of stroke/transient ischaemic attack. Less than $20 \%$ of the participants ever abused alcohol or smoked cigarettes. Age $(p=0.001)$, diastolic blood pressure $(p=0.025)$, serum low-density lipoprotein cholesterol $(p=0.044)$, and alcohol use $(p<0.001)$ were significantly different between patients with and those without IAC as presented in Table 3. In each patient, 13 arterial segments were examined 


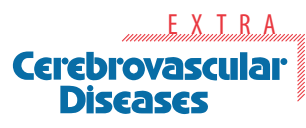

Table 2. Summary of demographic and clinical characteristics of the patients

\begin{tabular}{l|l}
\hline \begin{tabular}{l} 
Cerebrovasc Dis Extra 2018;8:26-38 \\
\hline DOI: $10.1159 / 000485195$
\end{tabular} & $\begin{array}{l}\text { @ } 2018 \text { The Author(s). Published by S. Karger AG, Basel } \\
\text { www.karger.com/cee }\end{array}$ \\
\hline $\begin{array}{l}\text { Olatunji et al.: Intracranial Arterial Calcification in Black Africans with Acute Ischaemic } \\
\text { Stroke }\end{array}$ & \\
\hline Male sex & $71(54.6)$ \\
Age & $5(3.8)$ \\
$\quad<40$ years & $61(46.9)$ \\
$\quad$ 40-65 years & $64(49.2)$ \\
Hypertension & $108(83.1)$ \\
Diabetes & $49(37.7)$ \\
Hyperlipidaemia & $67(51.5)$ \\
Past stroke/TIA & $36(27.7)$ \\
PAD & $12(9.2)$ \\
Smoking & $16(12.3)$ \\
Alcohol & $25(19.2)$ \\
\hline
\end{tabular}

Values are presented as $n$ (\%). TIA, transient ischaemic attack; PAD, peripheral artery disease.

Table 3. Comparison of vascular risk factors among patients with and without IAC

\begin{tabular}{|c|c|c|c|c|}
\hline \multirow[t]{2}{*}{ Parameter } & \multicolumn{2}{|l|}{ Calcification } & \multirow[t]{2}{*}{$t$ or $\chi^{2}$} & \multirow[t]{2}{*}{$p$ value } \\
\hline & yes & no & & \\
\hline Male sex & $65(91.6)$ & $6(8.4)$ & 0.567 & 0.452 \\
\hline Age, years & $64.09 \pm 12.34$ & $48.67 \pm 16.81$ & 3.53 & 0.001 \\
\hline \multicolumn{5}{|l|}{ Age strata } \\
\hline$<40$ years & $2(40)$ & $3(60)$ & 23.31 & $<0.001$ \\
\hline 40-65 years & $57(93.4)$ & $4(6.6)$ & & \\
\hline$>65$ years & 62 (96.9) & $2(3.1)$ & & \\
\hline Hypertension & $102(94.4)$ & $6(5.6)$ & 1.852 & 0.174 \\
\hline \multicolumn{5}{|l|}{$\mathrm{BP}, \mathrm{mm} \mathrm{Hg}$} \\
\hline SBP & $163.56 \pm 33.25$ & $183.22 \pm 27.60$ & -1.728 & 0.086 \\
\hline DBP & $96.50 \pm 15.58$ & $110.00 \pm 33.19$ & -2.269 & 0.025 \\
\hline Hyperlipidaemia & $65(97.0)$ & $2(3.0)$ & 3.327 & 0.068 \\
\hline \multicolumn{5}{|l|}{ FLP, mg/dL } \\
\hline TChol & $158.46 \pm 65.49$ & $142.11 \pm 34.83$ & 0.739 & 0.461 \\
\hline LDL-c & $107.27 \pm 41.65$ & $78.33 \pm 33.05$ & 2.035 & 0.044 \\
\hline $\mathrm{TG}$ & $114.12 \pm 59.05$ & $116.44 \pm 36.18$ & -0.116 & 0.908 \\
\hline HDL-c & $61.51 \pm 29.22$ & $66.89 \pm 17.72$ & -0.543 & 0.588 \\
\hline Diabetes mellitus & 45 (91.8) & $4(8.2)$ & 0.188 & 0.665 \\
\hline $\mathrm{RPG}, \mathrm{mg} / \mathrm{dL}$ & $158.80 \pm 66.75$ & $146.33 \pm 56.05$ & 0.546 & 0.586 \\
\hline Past stroke/TIA & $31(8.1)$ & $5(13.9)$ & 3.749 & 0.053 \\
\hline Alcohol use & $19(76.0)$ & $6(24.0)$ & 14.008 & $<0.001$ \\
\hline Smoking & $14(87.5)$ & $2(12.5)$ & 0.881 & 0.348 \\
\hline
\end{tabular}

Values are presented as $n(\%)$ or mean \pm SD. IAC, intracranial arterial calcification; BP, blood pressure; SBP, systolic blood pressure; DBP, diastolic blood pressure; FLP, fasting lipid profile; TChol, total cholesterol; LDL-c, low-density lipoprotein cholesterol; TG, triglyceride; HDL-c, high-density lipoprotein cholesterol; $\mathrm{RPG}$, random plasma glucose; TIA, transient ischaemic attack.

(i.e., right and left pre-cavernous ICA, cavernous ICA, and post-cavernous ICA; right and left MCA, ACA, and VA; and BA), hence a total of 1,690 arterial segments were evaluated for calcification in all the patients as shown in Table 4. Calcification was demonstrated in $497(23 \%)$ of the evaluated arterial segments. IAC was found in 121 patients $(93.1 \%)$, predominantly in the ICA $(86.1 \%)$ followed by the VA (9.3\%), MCA (2.4\%), BA (1.2\%), and ACA (1\%) as 


\section{Cerebrovascular \\ Diseases}

Fig. 3. Distribution of intracranial arterial calcification in the arterial segments. ICA, internal carotid artery; MCA, middle cerebral artery; ACA, anterior cerebral artery; VA, vertebral artery; BA, basilar artery.

Table 4. Pattern of calcifications in the intracranial arterial segments

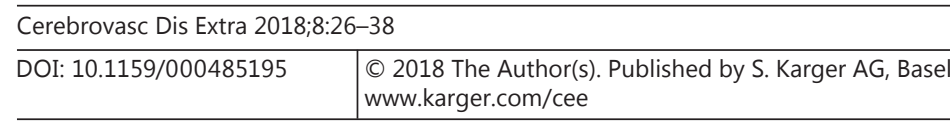

Olatunji et al.: Intracranial Arterial Calcification in Black Africans with Acute Ischaemic Stroke

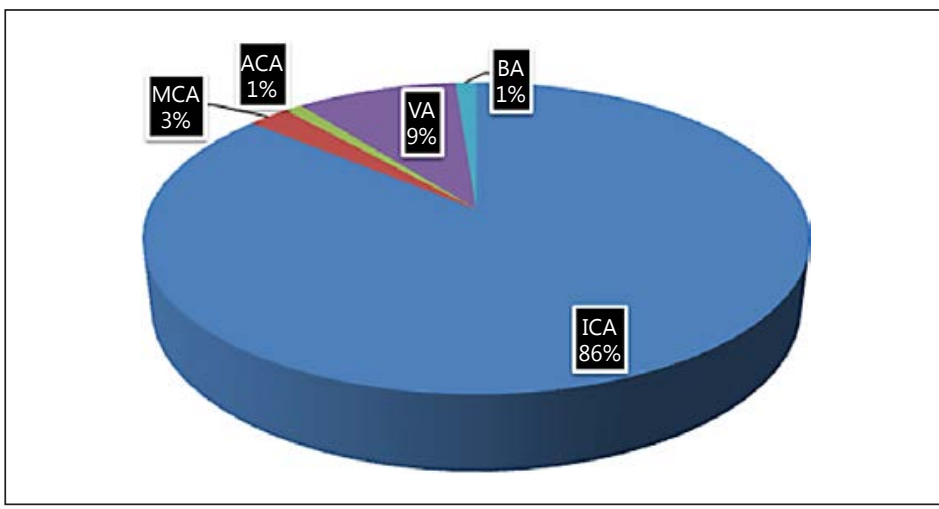

\begin{tabular}{|c|c|c|c|c|}
\hline \multirow{2}{*}{$\begin{array}{l}\text { Arterial } \\
\text { segment }\end{array}$} & \multicolumn{2}{|c|}{ Calcification } & \multirow[t]{2}{*}{$\chi^{2}$} & \multirow[t]{2}{*}{$p$ value } \\
\hline & $\begin{array}{l}\text { yes } \\
(n=497)\end{array}$ & $\begin{array}{l}\text { no } \\
(n=1,193)\end{array}$ & & \\
\hline \multicolumn{5}{|c|}{ Pre-cavernous ICA } \\
\hline Right & $23(17.7)$ & 107 (82.3) & 2.078 & 1.149 \\
\hline Left & $31(23.8)$ & $99(76.2)$ & 3.028 & 0.082 \\
\hline \multicolumn{5}{|l|}{ Cavernous ICA } \\
\hline Right & $104(80)$ & $26(20)$ & 38.68 & $<0.001$ \\
\hline Left & $104(80)$ & $26(20)$ & & \\
\hline \multicolumn{5}{|c|}{ Post-cavernous ICA } \\
\hline Right & $84(64.6)$ & $46(35.4)$ & 17.66 & $<0.001$ \\
\hline Left & $82(63.1)$ & $48(36.9)$ & 16.52 & $<0.001$ \\
\hline \multicolumn{5}{|l|}{ MCA } \\
\hline Right & $7(5.4)$ & $123(94.6)$ & 0.55 & 0.458 \\
\hline Left & $5(13.8)$ & $125(96.2)$ & 0.387 & 0.534 \\
\hline \multicolumn{5}{|l|}{ ACA } \\
\hline Right & $1(0.8)$ & $129(99.2)$ & 0.076 & 0.783 \\
\hline Left & $4(3.1)$ & 126 (96.9) & 0.307 & 0.580 \\
\hline \multicolumn{5}{|c|}{ Vertebral artery } \\
\hline Right & $22(16.9)$ & $108(83.1)$ & 1.970 & 0.160 \\
\hline Left & $24(18.5)$ & $106(81.5)$ & 2.189 & 0.139 \\
\hline Basilar artery & $6(4.6)$ & $124(95.4)$ & 0.468 & 0.494 \\
\hline
\end{tabular}

Values are presented as $n(\%)$. ICA, internal carotid artery; MCA, middle cerebral artery; ACA, anterior cerebral artery.

presented in Figure 3. Stratified by sex, the incidence of IAC was 91.6 and $94.9 \%$ in males and females, respectively. The mean scores of IAC were significantly higher in females $(7.3 \pm 2.6)$ than males $(6.3 \pm 2.9, p=0.045)$. Among those arterial segments with IAC, the calcium burden ranged from mild $(17.4 \%)$ to moderate $(52.1 \%)$ to severe $(30.6 \%)$. Mild, moderate, and severe degrees of calcification were found in 26.1 and 65.2\%; 58.9 and 28.3\%; and 15 and $6.5 \%$ of ICA and VA, respectively (Fig. 4). Severe degrees of calcification were not observed in the MCA, ACA, and BA. For the paired intracranial arteries, there was no significant difference in the severity of IAC on the right and left. Age $(p<0.001)$, diastolic blood pressure $(p=0.037)$, and alcohol use (0.046) were significantly different among the patients with mild, moderate, and severe degrees of IAC on univariate analysis (Table $5 \mathrm{a}$ ), but only age was persistently different on logistic regression analysis (odds ratio [OR]: 1.04, 1.004-1.079; $p=$ 


\section{Cerebrovascular \\ Diseases}

Fig. 4. Severity of intracranial arterial calcification (IAC) in the arterial segments. ICA, internal carotid artery; MCA, middle cerebral artery; ACA, anterior cerebral artery; VA, vertebral artery; BA, basilar artery.

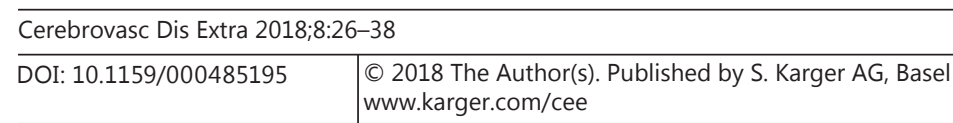

Olatunji et al.: Intracranial Arterial Calcification in Black Africans with Acute Ischaemic Stroke

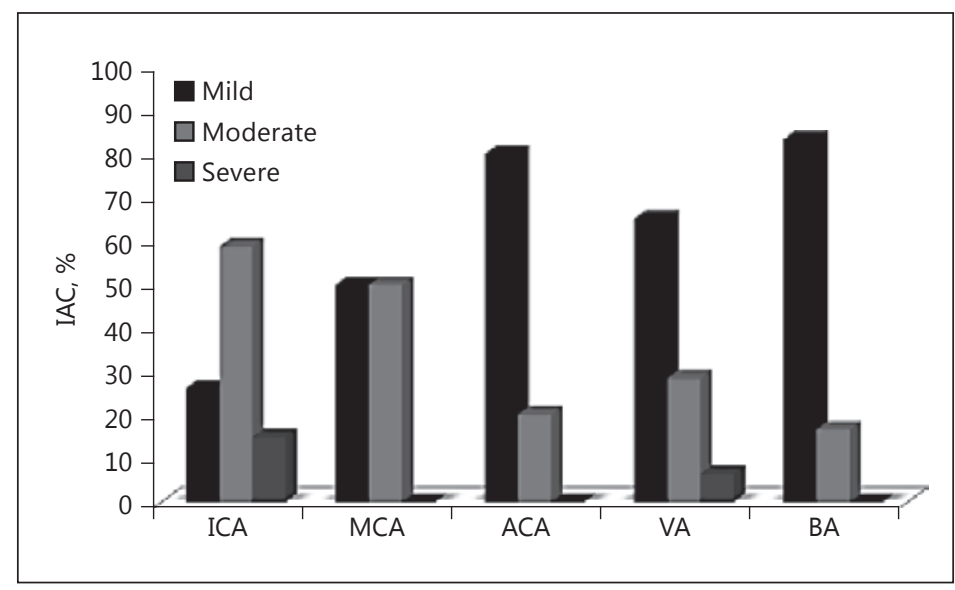

Table 5. Univariate analysis and multiple logistic regression analysis

a Univariate comparison of vascular risk factors among the groups of IAC severity

\begin{tabular}{lrrrr}
\hline Characteristic & \multicolumn{1}{l}{$\begin{array}{l}\text { Mild } \\
(n=21)\end{array}$} & $\begin{array}{l}\text { Moderate } \\
(n=63)\end{array}$ & $\begin{array}{l}\text { Severe } \\
(n=37)\end{array}$ & $p$ value \\
\hline Age, years & $54.58 \pm 9.07$ & $64.40 \pm 11.89$ & $69.03 \pm 11.78$ & $<0.001$ \\
Male sex & $14(66.7)$ & $36(57.1)$ & $15(40.5)$ & 0.117 \\
Hypertension & $18(85.7)$ & $50(79.4)$ & $14(37.8)$ & 0.213 \\
SBP, mm Hg & $167.95 \pm 36.68$ & $163.91 \pm 29.59$ & $160.49 \pm 37.52$ & 0.712 \\
DBP, mm Hg & $103.57 \pm 18.29$ & $96.37 \pm 13.75$ & $92.73 \pm 15.93$ & 0.037 \\
Diabetes mellitus & $8(38.1)$ & $22(34.9)$ & $15(40.5)$ & 0.850 \\
Hyperlipidaemia & $14(66.7)$ & $30(47.6)$ & $21(56.8)$ & 0.287 \\
LDL-c, mg/dL & $113.14 \pm 48.60$ & $106.38 \pm 39.06$ & $105.46 \pm 42.64$ & 0.775 \\
TChol, mg/dL & $166.29 \pm 83.97$ & $153.54 \pm 63.56$ & $162.41 \pm 57.70$ & 0.667 \\
Smoking & $2(9.5)$ & $11(17.5)$ & $1(2.7)$ & 0.051 \\
Alcohol use & $6(28.6)$ & $11(17.5)$ & $2(5.4)$ & 0.046 \\
\hline
\end{tabular}

Values are presented as $n(\%)$ or mean \pm SD. IAC, intracranial arterial calcification; SBP, systolic blood pressure; DBP, diastolic blood pressure; LDL-c, low-density lipoprotein cholesterol; TChol, total cholesterol.

b A multiple logistic regression model for predicting the severity of IAC

\begin{tabular}{lcc}
\hline & Odds ratio $(95 \% \mathrm{CI})$ & $p$ value \\
\hline Age, years & $1.04(1.004-1.079)$ & 0.029 \\
DBP & $0.98(0.955-1.010)$ & 0.204 \\
Alcohol use & $0.30(0.062-1.414)$ & 0.127 \\
\hline
\end{tabular}

IAC, intracranial arterial calcification; DBP, diastolic blood pressure.

$0.029)$ as shown in Table $5 \mathrm{~b}$. The number of IAC in the arterial segments was also associated with age $(p=0.036)$, diabetes mellitus $(p=0.004)$, and hyperlipidaemia $(p=0.001)$ but not with sex ( $p=0.153)$, hypertension $(p=0.940)$, or alcohol use $(p=0.666)$ as presented in Table 6a. On logistic regression analysis, age (OR: 1.09, 1.01-1.17), diabetes mellitus (OR: 3.43, 1.40-8.39), and hyperlipidaemia (OR: 0.24, 0.10-0.56) remained the independent predictors 
Table 6. Associations and determinants of number of calcifications in the intracranial arteries

a Associations of patients' characteristics with the number of arterial calcifications

\begin{tabular}{|c|c|c|c|c|}
\hline \multirow[t]{2}{*}{ Characteristic } & \multicolumn{2}{|l|}{ Calcifications } & \multirow[t]{2}{*}{$t^{*}$ or $\chi^{2}$} & \multirow[t]{2}{*}{$p$ value } \\
\hline & solitary $(n=50)$ & multiple $(n=71)$ & & \\
\hline \multicolumn{5}{|l|}{ Age } \\
\hline$<40$ years & $1(2)$ & $1(2)$ & 1.793 & 0.408 \\
\hline $40-65$ years & $27(54)$ & $30(42.9)$ & & \\
\hline$>65$ years & $22(44)$ & $40(56.4)$ & & \\
\hline Age, years & $61.3 \pm 11.88$ & $66.1 \pm 12.36$ & $-2.119^{*}$ & 0.036 \\
\hline \multicolumn{5}{|l|}{ Sex } \\
\hline Male & $23(46)$ & 42 (59.2) & 2.042 & 0.153 \\
\hline Female & $27(54)$ & $29(40.8)$ & & \\
\hline Hypertension & $42(84)$ & $60(84.5)$ & 0.006 & 0.940 \\
\hline Diabetes & $11(22)$ & 34 (47.9) & 8.417 & 0.004 \\
\hline Smoking & $3(6)$ & $11(15.5)$ & 2.584 & 0.108 \\
\hline Alcohol use & $7(14)$ & $12(16.9)$ & 0.187 & 0.666 \\
\hline PAD & $4(8)$ & 7 (9.9) & 0.123 & 0.726 \\
\hline Hyperlipidaemia & $36(72)$ & $29(40.9)$ & 11.454 & 0.001 \\
\hline Past stroke/TIA & $11(22)$ & $20(28.2)$ & 0.586 & 0.444 \\
\hline
\end{tabular}

Values are presented as $n(\%)$ or mean \pm SD. PAD, peripheral artery disease; TIA, transient ischaemic attack.

b A multiple logistic regression model for predicting multiple intracranial arterial calcifications

\begin{tabular}{lrc}
\hline & Odds ratio $(95 \% \mathrm{CI})$ & $p$ value \\
\hline Age & $1.09(1.011-1.166)$ & 0.025 \\
Diabetes & $3.43(1.404-8.391)$ & 0.007 \\
Hyperlipidaemia & $0.241(0.104-0.559)$ & 0.001 \\
Alcohol use & $1.782(0.541-5.873)$ & 0.343 \\
\hline
\end{tabular}

Table 7. Association of laterality of worst affected calcified paired arterial segment with laterality of infarct

\begin{tabular}{|c|c|c|c|c|c|}
\hline & \multicolumn{2}{|l|}{ Infarct } & \multirow[t]{2}{*}{$\chi^{2}$} & \multirow{2}{*}{$\begin{array}{l}\text { Odds ratio } \\
(95 \% \mathrm{CI})\end{array}$} & \multirow[t]{2}{*}{$p$ value } \\
\hline & right $(n=44)$ & left $(n=67)$ & & & \\
\hline \multicolumn{6}{|l|}{ Artery } \\
\hline Right $(n=42)$ & 25 & 17 & 11.165 & $3.87(1.72-8.71)$ & 0.001 \\
\hline Left $(n=69)$ & 19 & 50 & & & \\
\hline
\end{tabular}

of multiplicity of IAC (Table 6b). Overall, IAC was associated with age $(p<0.001)$, diastolic blood pressure $(p=0.03)$, diabetes mellitus $(p=0.02)$, elevated serum low-density lipoprotein $(p=0.04)$, and alcohol use $(p<0.001)$ but not with sex $(p=0.35)$. There was significant concordance between the side of the worst affected segment in paired arteries and the side of brain infarct (OR: 3.87, 1.72-8.71) as shown in Table 7 with an area under curve of 0.66 , sensitivity of $59.5 \%$, specificity of $72.5 \%$, positive predictive value of $56.8 \%$, and negative predictive value of $74.6 \%$ on the receiver operating characteristic curve analysis. 

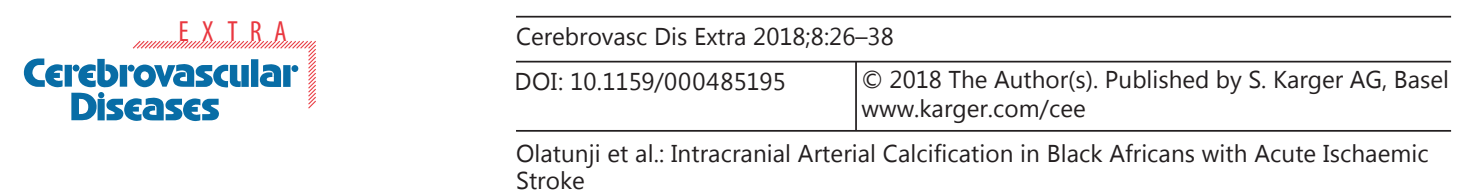

\section{Discussion}

In this study, a semi-quantitative analysis of atheromatous calcifications in 1,690 intracranial arterial segments was performed with CT images of 130 patients as surrogate for intracranial atherosclerotic disease (ICAD) on the premise that $80-90 \%$ of atherosclerotic plaques contain calcifications [4]. A high prevalence of IAC was found in our homogeneous group of black African patients in Nigeria. These calcifications of atheromatous plaques were more frequent in the bilateral carotid siphon and VA than other arterial segments, and more of mild-to-moderate degrees than severe. Age and diastolic blood pressure influenced the severity of IAC, while diabetes mellitus and hyperlipidaemia, in addition to age, were the determinants of singularity or multiplicity of calcified atheromatous plaques. The side with the worst severity of IAC mirrored the laterality of infarct with a high specificity and a negative predictive value in our cohort.

IAC are frequently observed on CT scans of the brain but poorly understood in native black Africans [5], despite the progressive increase in stroke incidence among them [2, 12]. IAC is an established indicator of ICAD, the most common mechanism of stroke globally $[3,5]$. The occurrence of ICAD, however, varies significantly among different races, being most prevalent in the non-Caucasian races. Asians are reported to have the highest burden of ICAD, while African Americans and Hispanics trail far behind [6-8]. The true burden and significance of ICAD among native black Africans is rather obscure in the literature. Its prevalence, however, is on the rise with evidence of over $200 \%$ increase from autopsy studies conducted 4 decades apart in Ibadan, Nigeria $[13,14]$.

The highest prevalence of IAC in patients with AIS in the literature was reported by Chen et al. [5] in China. They found IAC in $92.6 \%$ of 175 patients with AIS using a similar Hounsfield unit cutoff of 130 for calcifications on cranial CT. The present study observed IAC in $93.1 \%$ of the study sample, a marginally higher frequency than among the Chinese, but the highest rate reported to date to the best of our knowledge. However, both studies were hospital based in contrast to a population-based study by a group that also recorded a high prevalence rate, but among Caucasians. Bos et al. [15] reported a prevalence of $82.2 \%$ among a homogeneous asymptomatic cohort of Caucasians in the Rotterdam study which is among the highest rates in the literature for Caucasians. Their finding was contrary to the long-held - but changing mainstream opinion that ICAD was infrequent among Caucasians $[16,17]$.

However, there is a paucity of data on the prevalence of IAC in African Americans or other black populations in the diaspora for comparison. Despite this knowledge gap, there are suggestions of fundamental differences in the susceptibility factors at play for ICAD or stroke in native black Africans and African Americans sufficient to contradict the dogmatic depiction of the black race as a homogeneous group [14,18]. For instance, fewer than $20 \%$ of our patients ever smoked cigarettes or abused alcohol, unlike the exponentially higher rates among their counterparts in the diaspora [19]. Alcohol use, however, was significantly higher among patients with a mild severity of IAC in this study. A similar observation was made by Oladapo et al. [14] in their autopsy study of ICAD where alcohol use showed a significantly negative correlation with moderate and severe grades of atherosclerosis. Such subtle differences in the vascular risk factors between subsets of the black race may lead to varying patterns of pathologic manifestations probably mediated by environmental, dietary, or genetic factors. Recently published data by the SIREN (Stroke Investigation Research and Education Network) - a multinational case-control study in West Africa - and REGARDS (Reasons for Geographic and Racial Differences in Stroke) - a cohort study including African Americans and European Americans in the United States - revealed significant differences in stroke type and risk factors between African Americans and indigenous Africans [18]. 
In comparison to other studies with a high prevalence of IAC, the mean age of 63 years in our patients is lower $[5,15,20]$. However, this is not a surprise because the peak age for stroke among native black Africans is the middle age, an observation which may be connected with the lower life expectancy in many sub-Saharan African countries [12]. It also raises the possibility of an earlier onset of ICAD among native black Africans compared with other racial groups as noted previously [14]. However, it can be extrapolated that an even higher occurrence of IAC would have been found if there were more elderly subjects in the study. The association of age with presence and severity of IAC is significant in the present study in line with a unanimous pattern in the literature.

While many other authors limited their evaluation to the circle of Willis, this study also included the VA and distal ACA/MCA. The carotid siphon was more frequently involved than all other arterial segments in this study, a pattern consistent with findings from other studies. The rate of atherosclerotic calcifications of the VA in the present study, however, is lower than that reported previously in a study which used 90 Hounsfield units [21]. Taken together, the proximal inflow arteries appear to bear the brunt of the haemodynamic stress or other pathophysiologic mechanisms by which they are predisposed to atherosclerosis in our patients.

Older age, diabetes, and hyperlipidaemia were independent determinants of multiplicity of calcifications in the arterial segments evaluated in this study. Diabetes had the highest OR among them. These 3 risk factors are also culpable for pathological calcifications in other vascular beds such as coronary and peripheral microvasculatures and may be equally as important as hypertension in the genesis of ICAD in native black Africans as explained elsewhere [14]. There was a clear association between the laterality of the worst affected arterial segment and the laterality of infarct in this study. Some studies in other races concluded that there was no relationship between the location of infarct and the side of the most severely calcified vessel, while others reported a plausible association from their data [11, 22-24]. Calcified atheromatous plaques have been shown to play a direct causative role for infarct in the coronary circulation [25]. However, there is not enough evidence to adduce causality of infarct to intracranial atherosclerosis in this study, though the strong association was an interesting finding in our patients and directly aligns with the evidence in the coronary circulation. It is hoped that examination of the walls of intracranial arteries on MRI in patients with AIS will lay all controversies about causality of infarcts by ICAD to rest. The implications of IAC for black Africans with AIS will require diligent exploration in future studies which should combine noninvasive imaging modalities across multiple study sites in Africa.

The semi-quantitative scoring technique used in this study is an ultra-modification of the techniques described previously by other workers $[10,11,26]$. Essentially, the length of calcification was measured with electronic callipers in this study, scored according to predefined criteria, and added to the scores for extent and thickness by Mak et al. [11] to derive an overall composite score for the arterial segment. The maximum score therefore increased from 8 by Mak et al. [11] to 12 because of the need for a comprehensive semi-quantitative assessment of the calcifications in the arteries. Although an automatic volumetric quantitation is most desirable in principle, the close proximity of the arteries of interest to the bones of the skull base makes segmentation difficult and less feasible in routine clinical practice [27]. It has also been reported that visual scores correlate highly with quantitative measures, such as semiautomated scores and volume measurements, of intracranial ICA calcification on CT [27]. The pattern of severity of IAC in the arterial segments analyzed in this study is similar to that of other studies where a visual scoring technique was used $[10,11,26]$.

Therefore, we suggest that the addition of length of calcification as a quantitative third parameter, rather than a subjective measure like morphology of calcification as reported by some authors, would make visual scoring a less controversial technique for analysis of IAC $[28,29]$. The validity of the results may even be more reliable if the 3 parameters, namely 
extent, length, and thickness, were applied to every slice with IAC. Semi-quantitative visual scoring of IAC will enable stroke researchers from predominantly low-income black countries of sub-Saharan Africa with a huge research funding gap to do more with little and contribute data of acceptable quality to the literature on ICAD.

This study from Africa has bridged a major knowledge gap in the discourse on IAC vis-àvis ICAD as the study sample is homogeneously composed of native Africans, an understudied group. However, there are important limitations to consider. The descriptive cross-sectional methodology directed at AIS precluded any comparison of the rates of IAC with those in patients with haemorrhagic stroke and others without stroke. Furthermore, lipid plaque was not evaluated, partly because it was not an objective of the study but also because high-fieldstrength MRI which is unavailable in the study centre performs better than CT at detecting such plaques. So we can only assume that the ICAD burden in the group would definitely be higher if lipid plaques were sought.

\section{Conclusion}

The burden of IAC is high among black African patients with AIS and preferentially involves proximal inflow arteries. Age, diabetes mellitus, and hyperlipidaemia were persistently associated with IAC. Therefore, the determinants of large vessel atherosclerosis and the role of intracranial atherosclerosis in ischaemic stroke among black Africans should be explored in future multinational, multimodality studies.

\section{References}

1 Strong K, Mathers C, Bonita R: Preventing stroke: saving lives around the world. Lancet Neurol 2007;6:182187.

-2 Feigin VL, Lawes CM, Bennett DA, Barker-Collo SL, Parag V: Worldwide stroke incidence and early case fatality reported in 56 population-based studies: a systematic review. Lancet Neurol 2009;8:355-369.

-3 Gorelick PB, Wong KS, Bae HJ, Pandey DK: Large artery intracranial occlusive disease: a large worldwide burden but a relatively neglected frontier. Stroke 2008;39:2396-2399.

4 Berliner JA, Navab M, Fogelman AM, Frank JS, Demer LL, Edwards PA, et al: Atherosclerosis: basic mechanisms. Oxidation, inflammation, and genetics. Circulation 1995;91:2488-2496.

5 Chen XY, Lam WWM, Ng HK, Fan YH, Wong KS: Intracranial artery calcification: a newly identified risk factor of ischemic stroke. J Neuroimaging 2007;17:300-303.

6 Caplan LR, Gorelick PB, Hier DB: Race, sex and occlusive cerebrovascular disease: a review. Stroke 1986;17: 648-655.

7 Sohn YH, Cheon HY, Jeon P, Kang SY: Clinical implication of cerebral artery calcification on brain CT. Cerebrovasc Dis 2004;18:332-337.

8 Chen XY, Lam WW, Ng HK, Fan YH, Wong KS: The frequency and determinants of calcification in intracranial arteries in Chinese patients who underwent computed tomography examinations. Cerebrovasc Dis 2005;21: 91-97.

-9 Agatston AS, Janowitz WR, Hildner FJ, Zusmer NR, Viamonte M Jr, Detrano R: Quantification of coronary artery calcium using ultrafast computed tomography. J Am Coll Cardiol 1990;15:827-832.

10 Babiarz LS, Yousem DM, Wasserman BA, Wu C, Bilker W, Beauchamp NJ Jr: Cavernous carotid artery calcification and white matter ischemia. Am J Neuroradiol 2003;24:872-877.

11 Mak HK, Wong CW, Yau KK, Wong WM, Gu J, Khong PL, et al: Computed tomography evaluation of intracranial atherosclerosis in Chinese patients with transient ischaemic attack or minor ischaemic stroke-its distribution and associated vascular risk factors. J Stroke Cerebrovasc Dis 2009;18:158-163.

$\$ 12$ Owolabi MO, Akarolo-Anthony S, Akinyemi R, Arnett D, Gebregziabher M, Jenkins C, et al: The burden of stroke in Africa: a glance at the present and a glimpse into the future. Cardiovasc J Afr 2015;26:S27-S38.

13 Williams AO, Loewenson RB, Lippert DM, Resch JA: Cerebral atherosclerosis and its relationship to selected diseases in Nigerians: a pathological study. Stroke 1975;6:395-401.

14 Oladapo 00, Olusakin J, Ogun GO, Akang E: Atherosclerosis of the intracranial carotid arteries in Nigerians: a pilot autopsy study. Niger J Cardiol 2013;10:62-67. 
15 Bos D, van der Rijk MJM, Geeraedts TEA, Hofman A, Krestin GP, Witteman JCM, et al: Intracranial carotid atherosclerosis: prevalence and risk factors in the general population. Stroke 2012;43:1878-1884.

16 Sacco RL, Kargman D, Gu Q, Zamanillo MC: Race ethnicity and determinants of intracranial atherosclerotic cerebral infarction: the Northern Manhattan Stroke Study. Stroke 1995;26:14-20.

17 Arenillas JF: Intracranial atherosclerosis: current concepts. Stroke 2011;42:S20-S23.

18 Owolabi M, Sarfo F, Howard VJ, Irvin MR, Gebregziabher M, Akinyemi R, et al: Stroke in indigenous Africans, African Americans, and European Americans: interplay of racial and geographic factors. Stroke 2017;48: 1169-1175.

19 Agyemang C, Bhopal R, Bruijnzeels M: Negro, Black, Black African, African Carribean, African American or what? Labelling African origin population in the health arena in the 21st century. J Epidemiol Community Health 2005;59:1014-1018.

20 Bugnicourt JM, Leclercq C, Chillon JM, Diouf M, Deramond H, Canaple S, et al: Presence of intracranial artery calcification is associated with mortality and vascular events in patients with ischemic stroke after hospital discharge: a cohort study. Stroke 2011;42:3447-3453.

21 Pikija S, Magdic J, Hojs-Fabian T: Calcifications of vertebrobasilar arteries on CT: detailed distribution and relation to risk factors in 245 ischemic stroke patients. Biomed Res Int 2013;2013:918970.

-22 de Weert TT, Cakir H, Rozie S, Cretier S, Meijering E, Dippel DWJ, et al: Intracranial internal carotid artery calcifications: association with vascular risk factors and ischemic cerebrovascular disease. Am J Neuroradiol 2009;30:177-184.

-23 Yilmaz A, Akpinar E, Topcuoglu MA, Arsava EM: Clinical and Imaging features associated with intracranial internal carotid artery calcifications in patients with ischemic stroke. Neuroradiol 2015;57:501-506.

24 Wintermak M, Arora S, Tong E, Vittinghoff E, Lau BC, Chien JD, et al: Carotid plaque CT imaging in stroke and non-stroke patients. Ann Neurol 2008;64:149-157.

25 Schenker MP, Dorbala S, Hong ECK, Rybicki FJ, Hachamovitch R, Kwong RY, et al: Interrelation of Coronary calcification, Myocardial ischemia, and outcomes in patients with intermediate likelihood of coronary artery disease. Circulation 2008;117:1693-1700.

-26 Woodcock RJ Jr, Goldstein JH, Kallmes DF, Cloft HJ, Phillips CD: Angiographic correlation of CT calcification in the carotid siphon. Am J Neuroradiol 1999;20:495-499.

-27 Subedi D, Zishan US, Chappell F, Gregoriades ML, Sudlow C, Sellar R, et al: Intracranial carotid calcification on cranial computed tomography: visual scoring methods, semiautomated scores, and volume measurements in patients with stroke. Stroke 2015;46:2504-2509.

$>28$ Bos D, de Bruijne M, Lugt A: Letter by Bos et al regarding article, "Intracranial carotid calcification on cranial computed tomography: visual scoring methods, semiautomated scores, and volume measurements in patients with stroke". Stroke 2015;46:e254.

29 Subedi D, Zishan US, Wardlaw J: Response to Letter regarding article, "Intracranial carotid calcification on cranial computed tomography: visual scoring methods, semiautomated scores, and volume measurements in patients with stroke". Stroke 2015;46:e255. 